\title{
LA VALIDEZ DE LA PRUEBA INDICIARIA EN EL PROCESO PENAL ${ }^{1}$
}

\author{
Estefany Alvear ToBaR ${ }^{2}$ \\ ABOGADA EN LIBRE EJERCICIO PROFESIONAL EN ECUADOR
}

\section{RESUMEN:}

Con el paso del tiempo, el derecho procesal ha evolucionado y en consecuencia han aparecido diferentes clases de prueba, entre ellas la prueba indiciaria, actualmente la posición doctrinaria mayoritaria acepta el uso de esta prueba, pues afirma que evita que delitos, que no cuenta con prueba directa, queden en la impunidad. La finalidad de esta prueba es el llegar a una conclusión con respecto a su validez en base a otra prueba, lo que abre una brecha con respecto al análisis del juzgador, pues al no existir pruebas directas, aparentemente no se tendría la certeza de lo que ha ocurrido.

\section{PALABRAS CLAVE:}

Prueba, prueba indirecta, indicios, principio de inocencia, carga de la prueba.

1 Artículo recibido el 20 de enero de 2020 y aprobado el 20 de febrero de 2020.

2 La autora es investigadora del Instituto Ecuatoriano de Derecho Penal e Investigaciones Criminológicas.

ORCID: 0000-0001-6902-8544 


\section{ABSTRACT:}

Over time, Processual Law has evolved, in consequence it has appeared different classes of proof like the circumstantial evidence. Nowadays the majority doctrinal position accepts the use of it, because it says that it avoids that crimes that do not have direct proof remain unpunished. The purpose of this proof is to reach a conclusion about its validity in base of another proof, which open a gap in regard of the analysis of the judge because it does no exist direct evidence, so it is possible that the authority does not have certainty of the facts.

\section{KEY WORDS:}

Evidence, circumstantial evidence, indication, presumption of innocence, burden of proof 


\section{INTRODUCCIÓN}

La esencia de la prueba indiciaria es el llegar a una conclusión con respecto a la validez de esta en base a otra prueba, lo que abre una brecha bastante grande con respecto al raciocinio y análisis del juzgador, dado que, al no existir pruebas directas, tales como testigos, aparentemente no se tendría la certeza de lo que ha ocurrido, y como tal, se podría sentenciar como culpable a una persona que no ha cometido el ilícito.

Pensando en lo anterior, gran parte de las legislaciones del mundo han regulado la forma de aplicación de la prueba indiciaria y han señalado los requisitos que debe cumplir la prueba indiciaria para que sea considerada valida dentro del proceso penal. En el presente trabajo se hará un análisis del régimen ecuatoriano y español, con el fin de establecer diferencias y determinar mejoras en uno u otro sistema.

Otro de los problemas que aparece con el uso de la prueba indiciaria es la posible violación al principio de inocencia y la inversión de la carga de la prueba. El principio de inocencia menciona que toda persona que ha sido sometida a un proceso debe ser tratada como inocente hasta que exista una sentencia condenatoria que determine lo contrario, esto trae como consecuencia el hecho de que el procesado no tiene que demostrar su inocencia, sin embargo, se puede llegar a pensar que en los casos de aplicación de la prueba indirecta, es el procesado quien debe destruir los indicios propuestos por la acusación, lo que significaría una violación a las garantías básicas del debido proceso y, en consecuencia, en su debido momento se podría declarar la nulidad del mismo. 


\section{LA PRUEBA}

La prueba cumple una función importante en el proceso penal, pues sirve como medio idóneo para la reconstrucción conceptual y acreditación de un hecho que ha sucedido en el pasado y que le da contenido a la hipótesis acusatoria. Así, termina siendo ese instrumento sobre el cual debe apoyarse la comprobación de la reconstrucción conceptual de los hechos sometidos a un proceso penal ${ }^{3}$. En consecuencia, tiene la función de comprobar la producción de los hechos condicionales a los que el derecho consecuencias jurídicas, esto es determinar el valor de verdad de las proposiciones que describen la concurrencia de esos hechos condicionantes ${ }^{4}$.

Se conoce como prueba al conjunto de elementos que dan validez a una hipótesis, con los cuales se puede entender el suceso en el cual son constatadas circunstancias fácticas conforme a la $\operatorname{verdad}(\ldots)^{5}$.

Es así que, la prueba permite comprobar los hechos de la imputación delictiva, a través del procedimiento, con la finalidad de llevar al juzgador al convencimiento de los hechos y circunstancias materia de la infracción y la responsabilidad de la persona procesada. Es una actividad esencial del proceso sobre

3 Arocena, G., Balcarce, F., y Cesano, J. D. Prueba en materia penal. Buenos Aires, Editorial Astrea, 2009, p. 3.

4 Ferrer BeLtrÁn, J. La valoración racional de la prueba. Madrid, Marcial Pons, 2007, p. 30.

5 Gössel. "Sobre valoración probatoria, apreciación de la prueba y reglas de prueba", en De FigueIredo DíAs, et. al. El penalista liberal. Buenos Aires, Editorial Hammurabi, p. 96. 
la cual se fundamenta la actividad decisoria del Juez penal a través de la sentencia, dentro del debate contradictorio que exige el proceso penal ${ }^{6}$.

Se puede entonces decir que lo que se prueba son las afirmaciones sobre los hechos, no solo los hechos, pues se habla de prueba únicamente con respecto a cosas que hayan sido afirmadas y cuya exactitud es necesaria comprobar. De ahí que, la función de la prueba no sea la de averiguar sino verificar, lo cual a su vez permite identificar los actos de prueba de los actos de investigación ${ }^{7}$.

Para realizar esta diferenciación, hay que separar al proceso penal en dos partes, la fase investigativa y la de juicio; en la primera se realizan todas las indagaciones necesarias para determinar si existen suficientes elementos como para emitir una acusación e iniciar un proceso penal, aquí se practican actos de investigación. Por otro lado, en el juicio, se practica la prueba y se le da validez a la misma, por lo que estos ya pueden ser considerados actos de prueba. En este sentido, los jueces emitirán su dictamen basándose en las pruebas, no en los actos de investigación ${ }^{8}$, lo que permite deducir que todo elemento de cargo o descargo que no sea practicado en juicio no podrá ser considerado por los jueces al momento de tomar su decisión.

6 González Cano, M. I. y Romero Pradas, M. I. La prueba en el proceso penal. T. II. Valencia, Tirant lo Blanch, 2017, p. 28.

7 Pardo Iranzo, V. "La valoración de la prueba penal”, en Revista Bolivariana de Derecho. N. ${ }^{\circ}$ 2, 2006, p. 75.

8 SANChIS CRespo, C. La etapa preparatoria penal. Santa Cruz de la Sierra, Editorial El País, 2006, p. 22. 
En esta tarea de mostrar la verdad de las afirmaciones, pueden presentarse distintos medios de prueba, los más utilizados son el documental, testimonial y pericial; la primera se refiere a todos los documentos que han sido adjuntados al proceso y que pueden ser de utilidad tanto para la defensa, como para la parte acusatoria; el testimonio es la declaración dada por una persona, ante el juez, sobre sus percepciones de hechos en torno a los cuales gira el proceso; finalmente, la prueba pericial es un informe con respecto a circunstancias importantes para la investigación, realizado por personas con conocimientos especializados que el juez no posee 9 .

Al construir su versión de los hechos, el juez tiene que escoger los hechos extrayéndolos del conjunto de pruebas que tiene el proceso, ya sea por pedido de las partes o por iniciativa propia del juez. La decisión que tome el juzgador sobre los principales hechos del litigio se puede derivar tanto de pruebas directas como de pruebas de carácter presuntivo o indiciario ${ }^{10}$.

\section{Prueba directa}

La prueba directa es aquélla que permite al juez inferir la existencia de un hecho de manera inmediata y que no necesita mayor raciocinio ${ }^{11}$, porque ésta versa directamente a la hipótesis. Entonces lo único que se deberá observar es que la prueba sea

9 Armenta Deu, T. Lecciones de Derecho Procesal Penal. Madrid, Marcial Pons, 2009, p. 165.

10 Cruz Tejada, H. Nuevas tendencias de derecho probatorio. Santa Fe de Bogotá, Universidad de los Andes, 2015, p. 104.

11 JAUCHEN, E. Tratado de la prueba en materia penal. Buenos Aires, Editorial Rubinzal-Culzoni, 2002, p. 13. 
válida, de ahí la afirmación que el grado de confirmación de la hipótesis depende del grado de aceptabilidad de la prueba, la cual se determina mediante una serie de presupuestos e inferencias realizadas por el sujeto que utiliza la prueba, sobre las cuales establece el grado y credibilidad de la proposición que constituye el elemento ${ }^{12}$.

La valoración del grado de aceptabilidad de un elemento de prueba es el resultado de inferencias fundadas en premisas constituidas por distintas circunstancias con respecto a la formación de la prueba. Muchas veces las inferencias se basan en criterios científicos, en otras ocasiones en máximas de experiencia sobre valoraciones, análisis comportamientos, interpretaciones de expresiones lingüísticas, etc. Por lo cual no es normal que para llegar a esas inferencias el juez utilice esquemas lógicos establecidos para todos los casos, sin embargo, existe un criterio que siempre debe ser tomado en cuenta y es que el grado de aceptabilidad de la prueba está determinado por una o más inferencias vinculadas con el hecho ${ }^{13}$.

Respecto a la prueba directa, el Tribunal Supremo español ha mencionado que existe una preferencia hacia esta clase de prueba, que se sustenta en la menor complejidad que representa, puesto que es suficiente la indicación de la prueba, sin que sea preciso, en principio, un especial razonamiento, como, por el contrario, es necesario cuando de pruebas indiciarias se trata ${ }^{14}$.

\footnotetext{
12 TARuffo, M. Teoría de la prueba. Lima, ARA Editores, 2012, p. 92.

13 Ibíd. p. 93.

14 Tribunal Supremo De España. STS 8109/2007, de 12 de noviembre y STS 615/2016, de 8 de julio. La Sala de Casación del Tribunal Supremo determina que la realidad del hecho y la participación en
} 
el mismo del acusado puede ser establecida por la fórmula de siempre que concurran una serie de requisitos: a) Pluralidad de los hechos-base o indicios; b) Precisión de que tales hechos-base estén acreditados por prueba de carácter directo y ello para evitar los riesgos inherentes que resultarían de admitirse una concatenación de indicios, con la suma de deducciones resultantes que aumentaría los riesgos en la valoración; c) Necesidad de que sean periféricos respecto al dato fáctico a probar. No todo hecho puede ser relevante, así resulta preciso que sea periférico o concomitante con el dato fáctico a probar. No en balde, por ello, esta prueba indirecta ha sido tradicionalmente denominada como circunstancial, pues el propio sentido semántico, como derivado de circum y stare implica estar alrededor y esto supone no ser la cosa misma, pero si estar relacionado con proximidad a ella; d) Interrelación, la misma naturaleza periférica exige que los datos estén no solo relacionados con el hecho nuclear precisado de prueba, sino también interrelacionados; es decir, como notas de un mismo sistema en el que cada una de ellas represente sobre las restantes en tanto en cuanto formen parte de él. La fuerza de convicción de esta prueba dimana no sólo de la adición o suma, sino también de esta imbricación. e) Racionalidad de la inferencia; f) Expresión en la motivación del cómo se llegó a la inferencia en la instancia, pues solo cuando se contienen en la motivación de la sentencia los grandes hitos del razonamiento cabe el control extraordinario representado por el recurso de casación ante este Tribunal Supremo o en su caso, por el de amparo ante el Tribunal Constitucional y determinar si la inferencia ha sido de manera patente irracional, ilógica o arbitraria; pues de no mostrarse tal ilogicidad no cabe alterar la convicción del Tribunal de instancia formada con arreglo a la normativa. En relación con estas exigencias debe destacarse la importancia de los dos últimos requisitos señalados, que la doctrina de esta Sala ha insistido en resaltar y, en particular el de la explícita motivación jurídica de la inferencia deducida, especialmente exigible cuando se trata de esa clase de pruebas indirectas, a diferencia de los supuestos en los que el fundamento de convicción del Tribunal se sustenta en pruebas directas. 


\section{Prueba indirecta o indiciaria}

En ocasiones, existen ciertas complejidades en el momento de desarrollar la actividad probatoria, lo que lleva a la necesidad de acudir a la prueba indirecta, también llamada prueba circunstancial o colateral, en la cual los hechos indiciarios llevan a conseguir un razonamiento inductivo, formado en base a datos fácticos, que son acreditados por la parte que los alega. Se presentan como circunstancias que son acreditadas en el proceso para deducir otros derivados de un procedimiento logístico. Su función en el proceso penal es la de alcanzar la prueba de lo que se denomina elementos subjetivos o hechos de conocimiento, que tienen como función influir en la decisión judicial ${ }^{15}$.

En este sentido, la prueba indiciaria es una técnica de prueba que, en principio, es de aplicación general a cualquier tipo de delito, aunque resulta especialmente útil para la acreditación de determinadas clases de infracciones, tales como delitos de blanqueo de capitales, delitos contra la salud pública, delitos contra la libertad sexual; a través de la cual, el juzgador puede inferir sobre un hecho no conocido ${ }^{16}$.

El procedimiento para determinar la validez de la prueba indirecta nace a partir de enunciados probatorios y de ciertas regularidades causales, con lo que se construye una hipótesis sobre los hechos que explique esas pruebas mejor que cualquier otra hipótesis. Esas regularidades causales son leyes

15 González Cano, M. I., y Romero Pradas, M. I. La Prueba en el proceso penal. T. II. Valencia, Tirant lo Blanch, 2017, p. 95.

16 García Falconí, R., Pérez Cruz-Martín, A., y Guevara, A. El Proceso Penal, principios y garantías. Lima, ARA Editores, 2014, p. 204. 
probabilísticas y algunas incluso han sido obtenidas de manera mediata, por lo que la hipótesis explicativa tiene el carácter de posibilidad. En este sentido, la prueba indiciaria concluye la construcción de un supuesto, esto es un enunciado que se considera verdadero aun cuando no se sabe si lo es. Así, el grado de probabilidad suministrará un buen criterio para su justificación, esto no significa que no puedan tratarse supuestos verdaderos, mas bien, existen razones para esperar que el resultado de una inducción rigurosa sea fidedigno ${ }^{17}$.

Es entonces importante recalcar el papel del juzgador, pues tiene que realizar una operación intelectual para llegar al conocimiento, partiendo de uno o varios hechos básicos, realiza una inferencia razonable sobre hechos probados que se conecten entre sí, con el fin de generar conclusiones inequívocas de aspectos referenciales sobre una determinada conducta, pero que se muestran como elementos subjetivos necesarios para probar directamente hechos mediatos de la conducta reprochable ${ }^{18}$.

A pesar de que, la prueba indiciaria es usada en su mayoría por las partes acusadoras, con el fin de acreditar algún hecho constitutivo del delito, siendo utilizado como prueba de cargo para destruir la presunción de inocencia; sin embargo, también puede ser utilizado por las defensas para contrarrestar la prueba de la acusación o para acreditar algún hecho relevante en la concurrencia de una causa de atenuación de la responsabilidad penal, incluso simplemente para poder de manifiesto circunstancias o datos colaterales al

17 Gascón Abellán, M. Los hechos en el Derecho. 3. a ed. Madrid,
Marcial Pons, 2010, p. 104. 18

Belloch Julbe, J. A. "La prueba indiciaria”, en La sentencia penal. Madrid, 1992, p. 38. 
hecho criminal que sean consideradas favorables a la persona $\operatorname{procesada}^{19}$.

\section{Diferencia entre indicios y prueba indiciaria}

Atendiendo a Marcelo Sebastián Midón, el indicio es aquella prueba que, por vía de la reflexión y raciocinio, a partir de un hecho conocido, lleva por inducción-deducción a otros desconocidos. En este sentido, el indicio por sí solo no tiene valor alguno, pero cuando se relaciona con otras pruebas y siempre que sean graves, precisos y concordantes, constituyen una presunción ${ }^{20}$.

El indicio es entonces todo dato o circunstancia debidamente comprobada en la causa por vía de un medio de prueba. Este dato surge de los dichos del testigo, del contenido de la declaración del imputado, de un dictamen pericial, de una inspección judicial o cualquier otro medio ${ }^{21}$. Es posible que un hecho comprobado sea lógicamente derivable de una sola consecuencia, pero normalmente el indicio es significativo de pluralidad de hechos no conocidos, situación ambigua que solo puede superarse a través de una valoración unitaria, conjunta, global, que confluya en una indicación univoca que de la certeza del hecho a probar ${ }^{22}$.

19 García Falconí, R., Pérez Cruz-Martín, A., y Guevara, A. El Proceso Penal, principios y garantías. Lima, ARA Editores, 2014, p. 207.

20 Midón, M. Tratado de la prueba. Chaco, Librería de La Paz, 2007, p. 695.

21 Jauchen, E. Tratado de la prueba en materia penal. Buenos Aires, Editorial Rubinzal-Culzoni, 2002, p. 583.

22 Frondizi, R. y Daudet, M. G. Garantías y eficiencia en la prueba penal. La Plata, Editora Platense, 2000, p. 107. 
En este sentido, no se puede confundir la prueba indiciaria con los indicios pues la primera es una institución jurídico procesal de naturaleza compleja que pretende toda aquella actividad cognoscitiva y que incluye entre sus componentes al indicio; por su parte, un indicio es un concepto restringido de prueba indiciaria, que se manifiesta a través de un dato cierto, real, conocido, y que forma parte de un todo que es la prueba indiciaria ${ }^{23}$.

\section{Validez de la prueba indiciaria en el proceso penal Derecho comparado}

Desde la antigüedad la prueba indiciaria ha generado cierta desconfianza en comparación con la prueba directa, tanto que no se permitía a las partes procesales utilizarla si es que existía prueba directa ${ }^{24}$. En este sentido, la prueba indirecta suele generar ciertos problemas en derecho procesal porque debe cumplir ciertas particularidades que permitan determinar que esos indicios son lo suficientemente convincentes como para romper con el principio de inocencia, caso contrario se estaría violando los derechos del procesado.

\section{España}

Para evitar el abuso en los casos en los que no existe prueba directa, tanto el Tribunal Supremo español, como el Tribunal Constitucional han establecido ciertos criterios a ser tomados

23 PISFIL, D. “La prueba indiciaria en el proceso penal”, en Revista de la Maestría de Derecho Procesal. vol. V, Perú, 2014, p. 127.

24 De Miranda Vásquez, C. "Prueba directa vs. prueba indirecta: un conflicto inexistente", en Cuadernos de Filosofía del Derecho. Alicante, Universidad de Alicante, 2015, p.74. 
en cuenta al calificar a la prueba indiciaria como suficiente para dictar una sentencia condenatoria.

\section{Tribunal Supremo}

1. No pueden confundirse indicios con sospechas. Para que un indicio sea capaz de romper con la presunción de inocencia, estos deben ser probados y no simples probabilidades de que el hecho haya ocurrido. El indicio siempre tiene un presupuesto concreto, mientras que la presunción tiene un presupuesto abstracto y se refiere a algo general ${ }^{25}$.

2. No se puede fundamentar el fallo de la sentencia en su simple y puro convencimiento subjetivo. La motivación dada por los jueces no puede estar basada en lo que ellos creen que ha sucedido, sino que tiene que haber un razonamiento lógico para haber llegado a la verdad. Entonces, no se trata de que el juez, Tribunal o Jurado se convenzan de que el acusado cometió el hecho, sino de que expliquen por qué la suma de los indicios determinan la condena, en su caso, así como la solidez y concatenación de esos indicios, y no su debilidad ${ }^{26}$.

25 CAMACHO, D., y FLOR, J. Las presunciones como fundamento para dictar una sentencia de condena. Quito, Corporación de Estudios y Publicaciones, 2009, p. 9.

26 Tribunal Supremo de España. STS 3504/2019, de 4 de noviembre. La prueba indiciaria se nutre de la concatenación y unión de indicios que por sí solos no servirían para condenar, pero sí la suma de ellos y que llevan al Tribunal a la convicción de la autoría. Criterio que es admitido por la Sala Penal del Tribunal Supremo español, porque es consciente de que en muchos supuestos no existe prueba directa, 
3. La condena no puede fundarse en la creencia que los hechos ocurrieron como relatan. El Juez, Tribunal o Jurado deben estar convencidos de que los hechos ocurrieron como fueron relatados, sin duda alguna, porque la suma de esos indicios, que deben explicar con detalle, es lo que lleva a esa convicción.

4. Adecuada motivación acerca de la concurrencia de los indicios y su relevancia probatoria. El artículo 120, numeral 3 de la Constitución española determina que las sentencias tienen que ser motivadas, tomando en cuenta que lo lógico no determina la condena, sino que la suma de los indicios que se citan permite al Tribunal que, de una forma razonada y explicativa, fijar que los hechos se produjeron, con absoluta certeza porque si hubiera dudas no se podría condenar.

Así, en la operación deductiva deberán señalarse en primer lugar, cuáles son los indicios probados, y; en segundo término, cómo se deduce de ellos la participación del acusado en el tipo penal, de tal manera que cualquier otro Tribunal que intervenga con posterioridad pueda comprender el juicio formulado a partir de los indicios.

pero sí una realidad de la suma de varios indicios que determinan que la única forma de entender el hecho es por la autoría del acusado, cuya presunción de inocencia queda enervada no por una o varias pruebas directas, sino por varios indicios con entidad y peso suficiente como para concluir la convicción de la autoría. 


\section{Elementos y requisitos de la prueba indiciaria:}

\subsection{Elementos}

5.1.1. Una afirmación base o indicio;

5.1.2. Una afirmación consecuencia; y,

5. 1.3. Un enlace lógico y racional entre el primero y segundo elemento.

\subsection{Requisitos}

5.2.1. Que exista una pluralidad e indicios, se niega cualquier posibilidad de que un indicio aislado pudiera servir para construir una presunción.

5.2.2. Que la pluralidad de indicios estén demostrados mediante prueba directa, para lo cual el juzgador no puede construir una inferencia sobre meras afirmaciones de parte, pues sería arbitrario, en este caso se precisa objetividad.

5. 2.3. Que entre el indicio demostrado y el hecho que se trate de demostrar haya un enlace preciso, concreto y directo según las reglas del criterio humano.

5.2.4. Que el órgano judicial motive en su sentencia el razonamiento de cómo ha llegado a la certeza del hecho presunto.

6. La exigencia de la motivación en la sentencia respecto a la concurrencia de indicios y su consecuencia es más fuerte $y$, por lo tanto, debe ser más precisa que en los casos de prueba directa. La motivación debe ser clara y diáfana, tomando en cuenta que los indicios carecen 
de esa precisión. Para lo cual se deben explicar tanto las conclusiones obtenidas, como los elementos de prueba que conducen a las conclusiones y el intermental que le llevó a entender los hechos como probados ${ }^{27}$.

\section{Los indicios se alimentan entre sí para configurar la} condena. Se debe realizar el razonamiento inductivo propio de la prueba indiciaria. Esto exige un alto grado de motivación para que el procesado sepa por qué se le está condenando. Esa e vocación ideal de la relación entre los hechos -indicio y tema probandum-, es lo que permite inferir un término a partir de la comprobación del otro ${ }^{28}$.

\section{Si el órgano jurisdiccional no cumple con el deber constitucional de motivación es imposible tener acceso al proceso e inferencia llevado a cabo. El objetivo de este punto es saber si el razonamiento es arbitrario, absurdo o irracional.}

27 Tribunal Supremo de España. STS 506/2006, 16 de mayo. Es necesario que el órgano judicial precise cuáles son los indicios y cómo se deduce de ellos la autoría del acusado, de tal modo que cualquier otro Tribunal que intervenga con posterioridad pueda comprobar y comprender el juicio formulado a partir de tales indicios, siendo preciso, pues, que el órgano judicial explique no solo las conclusiones obtenidas, sino también los elementos de prueba que conducen a dichas conclusiones y el íter mental que le ha llevado a entender probados los hechos, a fin de que pueda enjuiciarse la racionalidad y coherencia del proceso mental seguido y constatarse que el Juez ha formado su convicción sobre una prueba de cargo capaz de desvirtuar la presunción de inocencia.

TRibunal SupREMo de EsPaÑa. STS de 18 de enero de 1995. 
9. Enlace lógico y racional entre el indicio o afirmación base y la afirmación consecuencia. Si el enlace no es lógico, racional y basado en la prueba directa, no se puede llegar a la afirmación consecuencia.

10. Debe existir certeza subjetiva. Se habla de certeza subjetiva que lleva a la convicción judicial cuando el Tribunal suma los indicios en su proceso final tras el juicio. La certeza subjetiva no es más que el hecho de que el razonamiento no sea ni absurdo, ni caprichoso, ni en definitiva un pensamiento construido por el Juzgador.

11. No es una sentencia de sospechas. La autoría que determina una condena no es la mejor explicación posible de lo ocurrido, por lo cual debe realizarse una sentencia de convicciones respecto a que la suma de indicios determina y lleva al Tribunal a concluir con seguridad que existe el cometimiento del delito por parte del acusado. Entre la comisión del delito y la autoría del ciudadano no va a bastar con que el Juzgador o Tribunal tenga la certeza íntima, subjetiva y personal, sino que a va ser absolutamente indispensable que se haga una apreciación lógica de la prueba practicada en el plenario, y posteriormente que de esta apreciación "en conciencia" y que se pueda ofrecer una explicación lógica y racional a la hora de motivar la Sentencia condenatoria, que haya fundamentado la aplicación de la denominada teoría de la prueba de indicios.

12. Se parte de la constatación de hechos mediatos para concluir otros inmediatos. 
13. Proceso deductivo. El Tribunal debe llevar a cabo un proceso deductivo que tiene que quedar plasmado en toda su extensión, permitiendo así un control de la racionalidad del hilo discursivo mediante el cual el órgano jurisdiccional afirma su inferencia. Entonces, tiene que quedar al descubierto el juicio de inferencia como actividad intelectual que sirve de enlace a un hecho acreditado y su consecuencia lógica.

14. Inducción o inferencia razonable. La inferencia no puede ser arbitraria, absurda o infundada, sino que debe responder a las reglas de la lógica y experiencia, de tal forma que la conclusión nazca de los hechos base acreditados.

15. Correlación entre los indicios. Los indicios deben mantener una correlación para que constituyen una cadena que vaya formando el inter para llegar al proceso mental de convicción que se conforma por la suma de los datos y la prueba de cada uno de ellos ${ }^{29}$.

16. Razonabilidad del discurso. Es obligación del Tribunal Supremo y del Tribunal Constitucional controlar la razonabilidad del discurso explicado por el órgano jurisdiccional que dictó la sentencia condenatoria basada en la prueba indirecta.

Conan Doyle, A. afirma que: Es esa correlación la que, con manifestación expresa o tácita, tiene que mostrar si en el criterio decisor elegido es posible o no la recognoscibilidad del tipo abstracto de derecho cuya violación se discute. CONAN DoYLE, A. "Coherencia narrativa y razonamiento judicial". 
17. Control de constitucionalidad. Puede realizarse en cualquier momento control de constitucionalidad de la racionalidad y solidez de la inferencia en que se sustenta la prueba indiciaria.

\section{Tipos de irracionalidad}

18. 1. La falta de lógica y la concurrencia de arbitrariedad o absurdo; $y$,

18.2. La falta de conclusividad.

La garantía de presunción de inocencia solo se verá vulnerada cuando la inferencia sea ilógica o tan abierta que en su seno quepa pluralidad de conclusiones alternativas que ninguna de ellas pueda darse por probada.

19. La conclusión de una inferencia presunta debe considerarse fuerte y determinada. La hipótesis va a resultar probada cuando esté dotada de un grado de confirmación prevaleciente respecto de otras inferencias presuntivas. Puede que una sola inferencia no sea capaz de romper la presunción de inocencia, pero una inferencia basada en otra le da firmeza a la conclusión.

20. Probabilidad prevaleciente. Para que la tesis acusatoria pueda prosperar se debe exigir una probabilidad prevaleciente con respecto a aquellas otras hipótesis explicativas de los mismos indicios, entre las que se puede contar la tesis fáctica de descargo ${ }^{30}$.

30 Tribunal Constitucional de España. STS 532/2019, de 4 de noviembre de 2019. 


\section{Tribunal Constitucional de España}

El Tribunal Constitucional considera que a falta de prueba directa se puede recurrir a la indirecta, bajo los siguientes términos:

1. Los hechos base o indicios tienen que estar plenamente probados

2. Los hechos constitutivos del delito deben deducirse de los hechos base.

3. El órgano judicial deberá exteriorizar los hechos que están acreditados y explicar su razonamiento o engarce lógico entre los hechos base y los hechos consecuencia ${ }^{31}$.

4. Este razonamiento debe estar asentado en las reglas del criterio humano o de la experiencia común ${ }^{32}$, esto es en una comprensión razonable de la realidad normalmente vivida y apreciada conforme a criterios colectivos vigentes $^{33}$.

31 Tribunal Constitucional de España. STC 49/1988, de 2 de marzo; STC 115/1998, de 1 de junio; STC 220/1998, de 16 de noviembre.

32 Tribunal Constitucional De España. STC 109/2009, de 11 de mayo de 2009. A falta de prueba directa de cargo también la prueba indiciaria puede sustentar un pronunciamiento condenatorio, sin menoscabo del derecho a la presunción de inocencia.

Tribunal Constitucional de España. STC 189/1998, de 28 de octubre. La falta de concordancia con las reglas del criterio humano -la irrazonabilidad- se puede producir, tanto por la falta de lógica o de coherencia de la inferencia, en el sentido de que los indicios constatados excluyan el hecho que de ellos se hace derivar o conduzcan naturalmente a él, como por el carácter no concluyente por excesivamente abierto, débil o indeterminado. 
La concurrencia de estos requisitos puede controlarse por el Tribunal Supremo o por el Tribunal Constitucional ${ }^{34}$.

Además, este Tribunal hace mención que las exigencias propias de la prueba indiciaria no tienen que trasladarse mecánicamente a la valoración de la concurrencia de un elemento normativo del tipo, pues la actividad intelectual del juez no pretende probar un hecho a través de otro hecho, sino que tiende, a comprobar que un juicio de valor es compatible con la prueba desarrollada en el seno del proceso, considerada en su conjunto ${ }^{35}$. Entonces, no se trata de ir de un hecho a otro a través de una inferencia sino de realizar una valoración jurídica en base a hechos que han sido $\operatorname{probados}^{36}$.

Tribunal Constitucional de España. STC 174/1985. Cuando la única prueba practicada es la indiciaria, puede surgir el problema de si nos encontramos ante una verdadera prueba de ese tipo, es decir, ante una actividad que conduce razonablemente a dar por ciertos unos hechos determinados, que incriminan al acusado, o si las conclusiones a que se pueda llegar por esta vía, no pasan de ser sospechas o datos de los que se desprenden visos o apariencias más o menos acusadoras de que una persona ha podido cometer un delito, pero que no constituyen una base suficientemente firme para que de ellas, pueda inferirse razonablemente la culpabilidad del acusado, y no suponen, por tanto, una prueba de cargo capaz de desvirtuar la presunción de inocencia consagrada por la Constitución.

34 Tribunal Constitucional de España. STC 182/1995, de 11 de diciembre.

35 Tribunal Constitucional de España. STC 2/2015, de 19 de enero.

36 Tribunal Constitucional de España. STC/ 148/1985, de 30 de octubre. En estos casos en los que un elemento normativo del tipo penal exige una valoración del juez, el derecho a la presunción de inocencia impone, como ya tempranamente tuvo la oportunidad de señalar este Tribunal, que esa valoración se realice «ponderando 
Así también, respecto a la presunción de inocencia, determina que el órgano jurisdiccional, al realizar la ponderación, debe tener en cuenta la versión o la prueba de descargo aportada por los acusados, pues el derecho a la presunción de inocencia se extiende a verificar si se dejó de someter a valoración la prueba de descargo aportada, lo que exige ponderar los distintos elementos probatorios $^{37}$.

\section{Ecuador}

En el caso de Ecuador, no suele ser común que las partes procesales usen indicios para comprobar sus hipótesis. Son pocos los abogados que acceden a esta prueba, tal fue el caso de la defensa de la víctima en el proceso N. ${ }^{\circ} 17282201803064$, sentencia con la cual los jueces ecuatorianos ratificaron que los indicios, usados bajo ciertos parámetros pueden constituir prueba válida ${ }^{38}$.

todos los medios de prueba obrantes en autos.

37 Tribunal Constitucional De España. STC 104/2011, de 20 de junio. La ponderación de elementos probatorios no implica que se realice de modo pormenorizado, ni que la ponderación se lleve a cabo del modo pretendido por el recurrente, requiriendo solamente que se ofrezca una explicación para su rechazo

Aunque, jurisprudencialmente los indicios fueron aceptados por la Corte Nacional de Justicia, los jueces de los Tribunales no solían aceptar este tipo de prueba. Sin embargo, la sentencia emitida dentro del proceso N. ${ }^{\circ} 17282201803064$, por el delito de secuestro extorsivo con resultado de muerte menciona: Es indudable que a más de los elementos probatorios ya esgrimidos ha existido variada prueba que también se ha evacuado por parte de los sujetos procesales, prueba que en el presente caso también se sujeta a criterios de univocidad de los indicios, es decir que debe existir concordancia, debido a que es muy improbable que esa univocidad probatoria surja de un solo indicio, es necesario que todos los indicios sirvan como evidencia en una valoración conjunta. Así, 
según la jurisprudencia, la certeza se deriva, en verdad, de la concurrencia concordante de una serie de indicios, que es lo que da univocidad a ese conjunto de elementos probatorios y no de la univocidad intrínseca de un indicio o de la mera multiplicidad de los mismos. (Conf. Pérez BARBERÁ, G. "La prueba por indicios según los distintos sistemas de enjuiciamiento penal. Su repercusión en la casación por agravio formal", en Cuadernos de Doctrina y Jurisprudencia Penal. N. ${ }^{\circ} 4$ y 5, ad hoc, pp. 406-407). Sólo los indicios unívocos pueden producir certeza, en tanto que el indicio anfibológico tornará en meramente verosímil o probable el hecho indicado, siendo insuficiente para fundar una condena en un proceso criminal. De la prueba testimonial que fue producida en esta Audiencia de Juzgamiento, no se cuenta a ningún testigo directo, ni del hecho ilícito del que habría sido víctima JCR, ni de la autoría del ciudadano procesado JPCS. En efecto, tal como se dijo, para que un testigo de los hechos que aqui se juzgan haya sido directo debió haber estado presente en el lugar de los hechos o muy cerca de él y debió percibir, a través de alguno de sus sentidos, el momento en que JCR era privada de su libertad por el ciudadano JCS o haber oído los gritos de ayuda de la víctima. Sin embargo, es cierto que, tal como tiene dicho la jurisprudencia para casos de delitos que implican una privación de la libertad, en los delitos como el secuestro extorsivo, caracterizados por su clandestinidad ya que, por lo general, se preparan o ejecutan en la esfera de intimidad de sus autores y partícipes, la prueba indiciaria reviste el carácter de privilegiada, ya que no siempre es posible lograr la comprobación directa del hecho $y$, evidentemente, prescindir de estos elementos generaría la impunidad de no pocas conductas ilícitas. Por ello, y partiendo de la consideración de que las reglas del proceso penal permiten utilizar como prueba los testimonios y el resto de los medios de prueba de carácter indirecto $y$, por ende, indiciario para acreditar la privación ilegítima de la libertad de la que habría sido víctima Juliana, así como la autoría de este hecho por parte de JCS, este Tribunal analiza toda la prueba aportada por las partes para fundar su decisión unánime a la que se arribó. Pero no puede perderse de vista que esta valoración de pruebas que tiene un carácter meramente indiciario deben seguir reglas y pasos muy estrictos debido a la ausencia de prueba directa, a saber: en primer lugar, los indicios deben estar verificados con certeza, en segundo lugar, se debe hacer una regla de inferencia que sea racional (en el sentido de una afirmación de la ciencia, técnica y o de la experiencia tenida por cierta con fundamento); en tercer lugar, la inferencia no debe conducir, con igual rigor racional, a una consecuencia distinta, porque estaríamos 
Bajo esta misma línea, la Corte Nacional de Justicia menciona en su Resolución N. ${ }^{\circ}$ 0620-2017 que:

(...) la prueba indiciaría busca alcanzar la certeza (...) a través de inferencias que permiten entablar el nexo causal entre la materialidad y la responsabilidad penal. Dotan de razonabilidad al fallo condenatorio en tanto y en cuanto no son simples conjeturas, pues para someterse a la aplicación de las reglas de la sana crítica por parte del juzgador deben ser probadas en la audiencia de juicio, para que solo así se obtenga una inferencia que permita determinar una conclusión válida de condena $(. . .)^{39}$.

Así también, la Resolución N. ${ }^{\circ}$ 1323-2017 del mismo órgano jurisdiccional establece tres requisitos básicos que deben ser analizados por el juez para obtener la inferencia válida de que se ha hablado ${ }^{40}$ :

ante indicios anfibológicos; en cuarto lugar, los otros medios de prueba u otros indicios deben también afirmar la conclusión a la que se arriba (prueba compleja), a la vez que estos otros medios probatorios $u$ otros indicios no deben conducir a conclusiones diferentes (prueba en contrario). Conf. MaIER, J. Derecho Procesal penal. Parte general. T. III.

39 Corte Nacional de Justicia del Ecuador. Resolución N. ${ }^{\circ} 620-$ 2017, Sala de lo Penal Militar, Penal Policial y Tránsito, juicio por peculado N. ${ }^{\circ}$ 7721-2016-0151.

40 Corte Nacional de Justicia del Ecuador. Resolución N. ${ }^{\circ} 1323-$ 2017, Sala de lo Penal Militar, Penal Policial y Tránsito, juicio por asesinato N. ${ }^{\circ}$ 17721-2014-1758. 


\section{Verificar la comisión de la infracción}

Para verificar la comisión de la infracción, los jueces tienen que hacer un análisis de los elementos del delito, una vez que se ha comprobado que la acción u omisión realizada por el sujeto ha sido típica, antijuridica y culpable y que además no existe ninguna causa de justificación, se puede afirmar que se ha cometido la infracción.

\section{Fundar la presunción en hechos reales y probados}

Para que los indicios tengan validez es necesario que exista un hecho probado a partir del cual el juzgador podrá realizar la inferencia. Si, por ejemplo, existe un asesinato, no bastará decir con que el procesado es el responsable porque se desconoce el lugar en el que estuvo mientras ocurrió el delito, tendrá que probarse, además, que existía una relación previa entre la víctima y el autor, de la cual se podría derivar un posible móvil.

\section{Utilizar indicios varios, relacionados, unívocos y directos} en la formación de las premisas que sirvan de base a la presunción

En este sentido es oportuno aclarar lo que menciona la doctrina al respecto, la regla prevé la posibilidad de que indicios o presunciones concordantes constituyan una prueba suficiente, incluso en los casos en que cada uno de ellos, valorado de forma individual, no sea eficaz para ello. Por otro lado, si hay varios indicios, no es necesario que todos lleven a la misma conclusión, la concordancia es necesaria, solo su ninguno de los indicios, de manera individual es idóneo 
para justificar la conclusión, pero si entre varios indicios, existen algunos concordantes, se puede considerar que es irrelevante la existencia de otros indicios que no concuerden con aquello ${ }^{41}$.

\section{Importancia de la prueba indiciaria}

La relevancia probatoria de la prueba indiciaria depende de si con base en él se puede llegar a una conclusión sobre un factum probandum $^{42}$. En este sentido, el indicio tiene que servir como premisa para una posible inferencia que permita formular una hipótesis incluyente, que non se deriva de manera obvia de la premisa, en este caso se habla de abducción, en el sentido que se trata de aquella inferencia que se funda sobre un indicio para formular una hipótesis relativa a un hecho que debe ser corroborado. Así, si la inferencia abductiva es exitosa, se puede decir que se ha encontrado un indicio. Por el contrario, si no se llega a la abducción sobre un hecho del litigio, entonces esta será irrelevante y no puede ser calificada como indicio.

Si se realiza el procedimiento en el párrafo anterior, la prueba indiciaria permite llegar al convencimiento de los argumentos planteados por las partes procesales. Al equipararse a la prueba directa, existen casos en los que resulta trascendental, como los delitos sexuales, los casos de desaparición o ejecuciones extrajudiciales, pues son ilícitos cometidos en su gran mayoría en la clandestinidad y, por ende, no existen testigos u otros medios de prueba.

41 Cruz Tejada, H. Nuevas tendencias del derecho probatorio. Santa Fe de Bogotá, Universidad de los Andes, 2015, pp. 113-114.

42 TARUfFo, M. Simplemente la verdad. Madrid, Marcial Pons, 2010, p. 140. 
La Corte Interamericana de Derechos Humanos ${ }^{43}$ también se ha pronunciado respecto a la importancia de la prueba indiciaria en los casos de violaciones a los derechos humanos, así lo deja ver en la sentencia del caso Velásquez Rodríguez vs Honduras, en la cual manifiesta:

La prueba circunstancial, los indicios y las presunciones, pueden utilizarse, siempre que de ellos puedan inferirse conclusiones consistentes sobre los hechos (...). Igualmente, la prueba indiciaria o presuntiva resulta de especial importancia cuando se trata de denuncias sobre desaparición forzada y en casos de ejecuciones extrajudiciales, debido a las dificultades probatorias que de éstas se derivan, cuando se enmarcan dentro de una práctica impulsada o tolerada por el Estado de graves violaciones a los derechos humanos, ya que esta forma de represión se caracteriza por procurar la supresión de todo elemento que permita comprobar el secuestro, el paradero y la suerte de las víctimas ${ }^{44}$.

Entonces, la prueba indiciaria, su correcto uso en juicio y la oportuna interpretación, plasmada en la sentencia, que le dan los

43 La CORTE IDH reitera que: Se trata de un medio probatorio utilizado en todos los sistemas judiciales y puede ser el único instrumento para que se cumpla el objeto y fin de la Convención Americana y para que la Corte pueda hacer efectivas las funciones que la misma Convención le atribuye, cuando las violaciones a los derechos humanos implican la utilización del poder del Estado para la destrucción de los medios de prueba directos de los hechos, en procura de una total impunidad o de la cristalización de una suerte de crimen perfecto.

44 Corte Interamericana de Derechos Humanos. Caso Velásquez Rodríguez vs. Honduras, Sentencia de fondo, de 29 de julio de 1998, parr. 141. 
jueces, permite que ciertos delitos no queden en la impunidad, por ende, evita que se violen los derechos de la víctima y a su vez, faculta al Estado a cumplir con su papel de garante ante la comisión de ilícitos, a través de la potestad sancionadora o ius puniendi que este posee.

Prueba indiciaria, vulneración al principio de inocencia e inversión de la carga de la prueba

\section{Principio de inocencia}

En todo proceso penal se asume la legalidad del actuar del procesado, en consecuencia, en principio no existe culpabilidad respecto de las acusaciones contra él formuladas. Como tal, la presunción de inocencia no puede ser agotada, a menos que existan pruebas suficientes como para demostrar la culpabilidad del acusado, más allá de toda duda razonable, lo que significa que, si al finalizar el proceso existen dudas respecto a la culpabilidad del procesado, se tiene que emitir una sentencia absolutoria ${ }^{45}$.

El principio de inocencia es la presunción que protege a la persona acusada del cometimiento de un delito, esto significa que se tiene que tratar al acusado como inocente durante los diferentes procesos a los que será sometido ${ }^{46}$. Justamente en virtud de este principio, la prueba completa de la culpabilidad del imputado debe ser suministrada por la acusación, imponiéndose

45 Esparza Leibar, I. El principio del proceso debido. Barcelona, J. M. Bosch Editor, 1995, p. 97-140.

46 Maier, J. B. J. Derecho Procesal Penal. T. I. Fundamentos. Buenos Aires, Editores del Puerto, 2004, p. 490. 
la absolución del procesado si la culpabilidad no queda suficientemente demostrada ${ }^{47}$. En este sentido, el principio de inocencia contiene un doble efecto, por un lado, que no se le puede exigir al procesado la actividad probatoria encaminada a demostrar su inocencia, y, por otro lado, correlativamente, será la parte acusadora quien deba probar la culpabilidad ${ }^{48}$.

Bajo esta línea garantista, tanto el Pacto Internacional de Derechos Civiles y Políticos, como la Convención Americana sobre Derechos Humanos establecen en sus ordenamientos jurídicos el principio de inocencia; el primero, en su artículo 14 determina:

Art. 14.2. Toda persona acusada de un delito tiene derecho a que se presuma su inocencia mientras no se pruebe su culpabilidad conforme a la ley ${ }^{49}$; el segundo en lo correspondiente a garantías judiciales.

Art. 8.- Garantías judiciales. - 2. Toda persona inculpada de delito tiene derecho a que se presuma su inocencia mientras no se establezca legalmente su culpabilidad $(\ldots)^{50}$.

47 Armenta Deu, T. Lecciones de Derecho Procesal Penal. 4. ${ }^{\text {a }}$ ed. Madrid, Marcial Pons, 2009, p. 237.

48 Barrientos Pacho, J. M. Prontuario Procesal penal. Barcelona, Ediciones Experiencia, 2010, p. 32.

49 Organización de las Naciones Unidas. Pacto Internacional de Derechos Civiles y Políticos, artículo 14.

50 Organización de los Estados Americanos. Convención Americana sobre Derechos Humanos, artículo 8. 
También el Tribunal Constitucional de España ${ }^{51}$ ha desarrollado varias ideas con respecto al principio de inocencia, que se desarrollan a continuación:

a) La presunción de inocencia se configura como un principio iuris tantum, lo que significa que puede ser desvirtuado con una mínima actividad probatoria o de cargo, las cuales deben ser aportadas por la acusación.

b) La mínima actividad probatoria debe practicarse con respeto a las garantías procesales y constitucionales.

c) Al Tribunal de instancia le corresponde apreciar libremente las pruebas practicadas en el juicio oral, sin que pueda el Tribunal Constitucional subrogarse en la valoración de las referidas pruebas convirtiéndose, por así decirlo, en una tercera instancia.

Con lo mencionado se puede determinar que el principio de inocencia constituye el punto de partida de toda la comprensión del proceso penal. La regulación de cada una de las actividades del proceso se encuentra al servicio de la idea de inocencia, lo que constituye un postulado esencial de la ciencia procesal y presupuesto de las demás garantías del proceso ${ }^{52}$. Al punto que, el derecho a la presunción de inocencia sólo puede ser desvirtuado

51 Tribunal Constitucional de España. ATC 84/1981, de 22 de julio.

52 García Falconí, R., Pérez-Cruz, A., y Guevara, A. El Proceso Penal, principios y garantías. Lima, ARA Editores, 2014, p. 52. 
cuando el juicio de culpabilidad se apoya en pruebas legalmente practicadas en el acto del juicio oral, bajo los principios de contradicción, igualdad, publicidad, oralidad e inmediación ${ }^{53}$.

\section{Vulneración al principio de inocencia}

Al respecto el Tribunal Supremo español ha sido claro al manifestar que no existe vulneración al principio de inocencia si es que el juez cumple con los parámetros establecidos al momento de valorar la prueba indiciaria.

El derecho a la presunción de inocencia no se opone a que la convicción judicial puedaformarse sobre la base de una prueba indiciaria; si bien para que esta prueba pueda desvirtuar dicha

53 Tribunal Constitucional de España. STC 128/2011, de 18 de julio. Tribunal Supremo de EspaÑa. STS 2679/2019, de 23 de julio. Cuando se denuncia la vulneración del derecho a la presunción de inocencia, se concreta en la verificación de si la prueba de cargo, en base a la cual el Tribunal sentenciador dictó sentencia condenatoria, fue obtenida, con respeto a las garantías inherentes del proceso debido, y por tanto: 1. En primer lugar, debe analizar el juicio sobre la prueba, es decir, si existió prueba de cargo, entendiendo por tal aquélla que haya sido obtenida, con respecto al canon de legalidad constitucional exigible, y que, además, haya sido introducida en el plenario, de acuerdo con el canon de legalidad ordinaria y sometida a los principios que rigen de contradicción, inmediación, publicidad e igualdad. 2. En segundo lugar, se ha de verificar el juicio sobre la suficiencia, es decir, si constatada la existencia de la prueba de cargo, ésta es de tal consistencia que tiene virtualidad de provocar el decaimiento de la presunción de inocencia. 3. En tercer lugar, debemos verificar el juicio sobre la motivación y su razonabilidad, es decir, si el Tribunal cumplió con el deber de motivación, o sea, si explicitó los razonamientos para justificar el efectivo decaimiento de la presunción de inocencia. 
presunción debe satisfacer las (...) exigencias constitucionales (...) pues, de otro modo, ni la subsunción estaría fundada en Derecho ni habría manera de determinar si el producto deductivo es arbitrario, irracional o absurdo, es decir, si se ha vulnerado el derecho a la presunción de inocencia al estimar que la actividad probatoria puede entenderse de cargo (... $)^{54}$.

Cuando se alega ante el Tribunal Supremo español una vulneración de la presunción de inocencia, lo que corresponde a los jueces es realizar una valoración de la sentencia emitida por el órgano jurisdiccional, de este modo sólo se considera vulnerado el derecho a la presunción de inocencia cuando la inferencia sea ilógica, irrazonable, no concluyente o tan abierta que quepa tal pluralidad de conclusiones alternativas que ninguna de ellas pueda darse por probada ${ }^{55}$.

\section{Carga de la prueba}

En todo proceso penal, se maneja el principio de presunción de inocencia, que como se dijo en líneas anteriores, significa que el imputado será inocente hasta que se demuestre lo contrario, de esto nace el hecho de que la carga de la prueba le corresponde a la acusación, es decir, el procesado no tiene que probar su inocencia

\footnotetext{
54 Tribunal Supremo de España. STS 1041/2015, de 23 de marzo.

55 Tribunal Constitucional de España. STC 229/2003, de 18 de diciembre. Por lo que, este Tribunal afirma que ha de ser especialmente cauteloso, por cuanto son los órganos judiciales los únicos que tienen un conocimiento preciso, completo y adquirido con todas las garantías de la actividad probatoria, especialmente por factores derivados de la inmediación.
} 
porque intrínsecamente ya es inocente, es la acusación la que tiene que probar cada una de sus afirmaciones. Sin embargo, cuando se juzga en base a prueba indiciaria se presenta una particularidad pues, aparentemente es el sujeto pasivo quien debería destruir esos indicios ${ }^{56} \mathrm{y}$, por ende, se verían violentados los principios básicos procesales.

De ahí viene la importancia de aplicar cada uno de los presupuestos establecidos tanto por el Tribunal Supremo español, como la Corte Nacional de Justicia ecuatoriana, dependiendo la territorialidad. Solo así, la valoración de las manifestaciones exculpatorias del acusado no implicarían invertir la carga de la prueba porque existen otros indicios relevantes de cargo que, por sí mismos, permiten deducir racionalmente su intervención en los hechos ${ }^{57}$. En este sentido, no se trata de que el acusado deba acreditar su inocencia, sino que, una vez practicada la prueba indiciaria, esta tiene fuerza suficiente para destruir la presunción de inocencia, por lo que la supuesta prueba practicada por el procesado no es

56 Garrido Carrillo, F. J. “Indicios, presunciones e inversión de la carga de la prueba", en Estudios Jurídicos, penales y criminológicos en Homenaje al Prof. Lorenzo Morillas Cueva. vol. II. Madrid, Editorial Dykinson, p. 2053.

57 Tribunal Constitucional de España. STC 135/2003, de 30 de junio y STC 170/2005, de 20 de junio. En estos casos se trata únicamente de constatar que, existiendo prueba directa de los elementos objetivos del tipo delictivo y una prueba indiciaria constitucionalmente válida, suficiente y convincente, acerca de la participación en el hecho del acusado, a dicha prueba no se le contrapone una explicación racional y mínimamente verosímil, sino que, por el contrario, las manifestaciones del acusado por su incoherencia interna y por su incredibilidad, no solamente no desvirtúan, sino que refuerzan la convicción racionalmente deducida de la prueba practicada. 
como tal una prueba sino más bien una interpretación alternativa con el fin de justificar lo que ya han probado los indicios ${ }^{58}$. Por lo que, la parte que se ve afectada por los indicios alegados, puede presentar pruebas (contraindicios) que desvirtúen el hecho resultante de la inferencia a que se deduce de la prueba indiciaria, lo que es comprensible por la simple razón de que la persona tiene derecho a probar, a pesar de ser el procesado ${ }^{59}$.

\section{Conclusiones}

La prueba cumple un papel fundamental dentro del proceso penal pues busca llevar al juzgador al convencimiento de los hechos y circunstancias materia de la infracción y la responsabilidad de la persona procesada. En este afán por llegar a ese convencimiento pueden aparecer pruebas directas e indirectas, que a pesar de ser contrarias la una de la otra, ambas son aceptadas en el proceso penal.

La prueba indirecta hace que el juez llegue al convencimiento de los hechos a través de una reflexión en torno a los demás medios de prueba, es decir, la prueba indiciaria por sí sola no lleva a sacar ninguna conclusión, justamente porque carece de la calidad de prueba directa.

La inferencia que realice el juez cuando cuenta con pruebas indirectas es muy importante pues, con el fin de evitar que el delito quede en la impunidad, puede quebrantar el debido proceso;

58 Tribunal Supremo de España. STS 1041/2015, de 23 de marzo.

59 Vidaurri ArÉChiga, M. “Consideraciones en torno a la prueba indiciaria", en Revista de Ciencias Jurídicas. N. ${ }^{\circ} 149$. Ciudad de México, 2019, p. 92. 
y viceversa. En este sentido siempre tendrá que verificar que se cumplan taxativamente cada uno de los requisitos establecidos en su ordenamiento jurídico.

Tanto el ordenamiento jurídico español como el ecuatoriano tienen requisitos que deben ser cumplidos para que la prueba indiciaria sea considerada válida, sin embargo, llama la atención el ultimo pronunciamiento emitido por el Tribunal Supremo de España pues establece características, elementos y requisitos de la prueba indiciaria, como complemento, el Tribunal Constitucional español también ha emitido sentencias sobre el tema. Por su parte, en Ecuador únicamente existen pronunciamientos emitidos por la Corte Nacional de Justicia, en los cuales se enuncian tres características, los cuales en la mayoría de los casos no resultan una guía adecuada para los juzgadores.

El Tribunal Supremo de España, a diferencia de la Corte Nacional de Ecuador, se ha preocupado no solo por las características que debe tener la prueba indiciaria, sino que también ha marcado el camino que debe seguir el juez en la práctica de la prueba y al momento de redactar la sentencia, tratando de evitar a como dé lugar la violación de derechos constitucionales o la impunidad en los delitos.

Si bien es cierto, la importancia del uso de la prueba indiciaria está en el hecho de evitar la impunidad en ciertos delitos, sin embargo, de nada sirve juzgar con prueba indiciaria si en un futuro se alegan violaciones al debido proceso y este termina siendo nulo, por esta razón, lo más importante dentro de la aplicación de la prueba indirecta es que el juez compruebe que esta cumple con cada una de las características, requisitos y elementos necesarios para que tenga validez. 
Resulta interesante como los juristas que ejercen en el Ecuador sienten cierto recelo por el uso de la prueba indiciaria, aún creen que esta debe ser usada en última instancia o simplemente no ser usada por la poca objetividad que aparentemente podría tener. La Corte Nacional de Justicia del Ecuador se pronunció al respecto hace poco más de dos años, con lo cual resulta bastante lógico que no se haya difundido por completo el uso que se le puede dar a la misma. Realidad muy diferente a la de España, país en el cual se ha normalizado el uso de la prueba indiciaria. 


\section{REFERENCIAS BIBLIOGRÁFICAS}

ARMENTA DEU, Teresa, Lecciones de Derecho Procesal Penal. Madrid, Marcial Pons, 2009.

AROCENA, Gustavo, Balcarcé,Fabián, y, Cesano, José Daniel.Prueba en materia penal. Buenos Aires, Editorial Astrea, 2009.

BARRIENTOS PACHO, Jesús María. Prontuario Procesal Penal. Barcelona, Ediciones Experiencia, 2010.

BELlOCH JULBE, Juan Alberto. La prueba indiciaria, en la sentencia penal. Madrid, 1992.

CAMACHO, Daniela, y FLOR, Jaime. Las presunciones como fundamento para dictar una sentencia de condena. Quito, Corporación de Estudios y Publicaciones, 2009.

CONAN DOYLE, Arthur. Coherencia narrativa y razonamiento judicial, Proceso y Narración. Teoría y Práctica del narrativismo jurídico. Lima, Palestra Extramuros, 2020.

CORTE INTERAMERICANA DE DERECHOS HUMANOS. CaSo

Velásquez Rodríguez vs. Honduras, Sentencia de fondo, 29 de julio de 1998. 
CORTE NACIONAL DE JUSTICIA DEL ECUADOR. Resolución N. ${ }^{\circ}$ 1323-2017, Sala de lo Penal Militar, Penal Policial y Tránsito.

CORTE NACIONAL DE JUSTICIA DEL ECUADOR. Resolución N. ${ }^{\circ}$ 620-2017, Sala de lo Penal Militar, Penal Policial y Tránsito.

CRUZ TEJADA, Horacio. Nuevas tendencias de Derecho probatorio. Santa Fe de Bogotá, Universidad de los Andes, 2015.

DE MIRANDA VÁsQUEZ, Carlos. "Prueba Directa vs. Prueba Indirecta: un conflicto inexistente", Cuadernos de Filosofía del Derecho. Alicante, Universidad de Alicante, 2015.

ESPARZA LEIBAR, Iñaki. El principio del proceso debido. Barcelona, J. M. Bosch Editor, 1995.

FERRER BELTRÁN, Jordi. La valoración racional de la prueba. Madrid, Marcial Pons, 2007.

FRONDIZI,Román,y DAUDET, María Gabriela. Garantías y eficiencia en la prueba penal. La Plata, Editora Platense, 2000.

GARCía FALCONÍ, Ramiro, PÉREZ CRUZ-MARTín, Agustín, y GUEVARA, Alba. El Proceso Penal, principios y garantías. Lima, ARA Editores, 2014.

GARRIDO CARRILLO, Francisco Javier. "Indicios, presunciones e inversión de la carga de la prueba”, Estudios Jurídicos, penales y criminológicos en Homenaje al Prof. Lorenzo Morillas Cueva. vol. II. Madrid, Editorial Dykinson, s/f. 
GASCÓN ABELlÁN, Marina. Los hechos en el Derecho. 3. ${ }^{a}$ edición. Madrid, Marcial Pons, 2010.

GONZÁLEZ CANO, María Isabel, y ROMERO PRADAS, María Isabel. La Prueba en el proceso penal. Tomo II. Valencia, Tirant lo Blanch, 2017.

GÖSSEL. "Sobre valoración probatoria, apreciación de la prueba y reglas de prueba", De Figueiredo Días, et al. El penalista liberal. Buenos Aires, Editorial Hammurabi, s/f.

JAUCHEN, Eduardo. Tratado de la prueba en materia penal. Buenos Aires, Editorial Rubinzal-Culzoni, 2002.

MAIER, Julio. Derecho Procesal Penal. Tomo I. Fundamentos. Buenos Aires, Editores del Puerto, 2004.

MIDón, Marcelo. Tratado de la prueba. Chaco, Librería de La Paz, 2007.

ORGANIZACIÓN DE ESTADOS AMERICANOS. Convención Americana sobre Derechos Humanos.

ORGANIZACIÓN DE LAS NACIONES UNIDAS. Pacto Internacional de Derechos Civiles y Políticos.

PARDO IRANZO, Virginia. "La valoración de la prueba penal", Revista Bolivariana de Derecho. N. ${ }^{\circ}$ 2, 2006.

PISFIL, Daniel. "La prueba indiciaria en el proceso penal", Revista de la Maestría de Derecho procesal. vol. V, Perú, 2014. 
SANCHIS CRESPO, Carolina. La etapa preparatoria penal. Santa Cruz de la Sierra, Editorial El País, 2006.

TARUFFO, MICHELE. Simplemente la verdad. Madrid, Marcial Pons, 2010.

. Teoría de la prueba. Lima, ARA Editores, 2012.

TRIBUNAL CONSTITUCIONAL DE ESPAÑA. ATC 84/1981, de 22 de julio de 1981.

TRIBUNAL CONSTITUCIONAL DE ESPAÑA. STC 148/1985, de 30 de octubre de 1985.

TRIBUNAL CONSTITUCIONAL DE ESPAÑA. STC 182/1995, de 11 de diciembre de 1995.

TRIBUNAL CONSTITUCIONAL DE ESPAÑA. STC 49/1988, de 2 de marzo de 1988.

TRIBUNAL CONSTITUCIONAL DE ESPAÑA. STC 115/1998, de 1 de junio de 1998.

TRIBUNAL CONSTITUCIONAL DE ESPAÑA. STC 189/1998, de 28 de octubre de 1998.

TRIBUNAL CONSTITUCIONAL DE ESPAÑA. STC 220/1998, de 16 de noviembre de 1998.

TRIBUNAL CONSTITUCIONAL DE ESPAÑA. STC 135/2003, de 30 de junio de 2003. 
TRIBUNAL CONSTITUCIONAL DE ESPAÑA. STC 229/2003, de 18 de diciembre de 2003.

TribunAL CONSTITUCIONAL DE ESPAÑA. STC 170/2005, de 20 de junio de 2005.

TRIBUNAL CONSTITUCIONAL DE ESPAÑA. STC 109/2009, de 11 de mayo de 2009.

TRIBUNAL CONSTITUCIONAL DE ESPAÑA. STC 104/2011, de 20 de junio de 2011.

TRIBUNAL CONSTITUCIONAL DE ESPAÑA. STC 128/2011, de 18 de julio de 2011.

TRIBUNAL CONSTITUCIONAL DE ESPAÑA. STC 2/2015, de 19 de enero de 2015.

TRIBUNAL DE GARANTÍAS PENALES DEL DISTRITO METROPOLITANO DE QUITO. Sentencia del proceso N. ${ }^{\circ}$ 17282201803064 .

TRIBUNAL SUPREMO DE ESPAÑA. STS de 18 de enero de 1995.

TRIBUNAL SUPREMO DE ESPAÑA. STS 506/2006, 16 de mayo de 2006.

TRIBUNAL SUPREMO DE ESPAÑA. STS 8109/2007, de 12 de noviembre de 2007. 
TRIBUNAL SUPREMO DE ESPAÑA. STS 1041/2015, de 23 de marzo de 2015.

TRIBUNAL SUPREMO DE ESPAÑA. STS 615/2016, de 8 de julio de 2016.

TRIBUNAL SUPREMO DE ESPAÑA. STS 2679/2019, de 23 de julio de 2019.

TRIBUNAL SUPREMO DE ESPAÑA. STS 3504/2019, de 4 de noviembre de 2019.

TRIBUNAL SUPREMO DE ESPAÑA. STS 532/2019, de 4 de noviembre de 2019.

VIDAURRI ARÉCHIGA, Manuel. Consideraciones en torno a la prueba indiciaria, Revista de Ciencias Jurídicas. N. ${ }^{\circ} 149$. Ciudad de México, 2019. 